\title{
Biomechanical analysis on different fixation techniques for treatment of mandibular body fractures
}

\author{
Marcela Ribeiro', Andrezza Lauria', Fábio Ricardo Loureiro Sato ${ }^{1}$, Roger William Fernandes Moreira ${ }^{1}$
}

${ }^{1}$ Area of Oral and Maxillofacial Surgery, Piracicaba Dental School, University of Campinas, Piracicaba, SP, Brazil

\begin{abstract}
Aim: To biomechanically analyze two fixation techniques in polyurethane hemi-mandibular body fractures, using a universal testing machine. Methods: The study employed 10 polyurethane hemi-mandible replicas, which simulated simple fractures of the mandibular body, divided into two groups: one group comprised 5 hemi-mandibles with two $2.0 \mathrm{~mm}$ system plates in the tension and compression zones, while the other group contained 5 hemi-mandibles with an Erich bar and a $2.0 \mathrm{~mm}$ system plate in the tension and neutral zones, respectively. Data were analyzed statistically by the Student's t-test $(\alpha=0.05)$ Results: The test results indicated that the fixation using $2.0 \mathrm{~mm}$ system plates offered significantly more resistance to the loads and presented significantly larger displacement compared to the fixation using just one $2.0 \mathrm{~mm}$ system plate and the Erich bar. Conclusions: It may be concluded that the use of two plates in the $2.0 \mathrm{~mm}$ system had greater mechanical strength than a single $2.0 \mathrm{~mm}$ plate combined with an Erich bar. Clinically, it is known that both techniques can provide good results, but patients receiving the combination of Erich bar and one plate are required to be more cooperative during the postoperative period, especially with respect to the prescribed diet in order to avoid failures in this system.
\end{abstract}

Keywords: mandibular fractures, bone plates, internal fixation of fractures.

\section{Introduction}

Mandibular body fractures are considered common but there are discrepancies among the studies, such as epidemiological surveys, regarding their incidence. Martini et al. ${ }^{1}$ (2006), noticed a higher incidence of mandibular body fracture (30.9\%). Atilgan et al. ${ }^{2}$ (2006) observed that mandibular body fractures were more frequent in adults than in children, but occurred in only $12 \%$ of the 532 Turkish patients included in the study.

In the surgical treatment of facial fractures, there are principles that should be

Received for publication: December 26, 2012 Accepted: April 01, 2013

Correspondence to: Andrezza Lauria Departamento de Diagnóstico Oral Faculdade de Odontologia de Piracicaba - UNICAMP Avenida Limeira, 901, CEP:13414900 Caixa Postal: 52, Piracicaba, SP, Brasil Phone: +55 1921065708 E-mail: andrezzalauria@gmail.com followed for a successful outcome: fracture reduction (replacement of bone segments in their correct anatomical positions), fixation and containment of bone segments and immobilization at the fracture site $^{3}$. Specifically to the mandible, the treatment can follow a more conservative approach such as the maxillomandibular fixation (MMF) with stainless steel wires or the procedures under general anesthesia with surgical exploration, reduction and fixation of the fracture ${ }^{4}$.

The use of mini plates has been changing the treatment of fractures in the last two decades, in addition to various methods of mandible fixation, such as 
compressive and non-compressive plates, reconstructive plates, isolated screws, either by intra or extra oral access, have been used with varying degrees of success ${ }^{6}$. Regarding to mandibular body fixation, Milloro et al. ${ }^{7}$ (2009) reported that for simple linear fractures, the application of a single mini plate of the $2.0 \mathrm{~mm}$ system along the lower edge, combined with a bar, is usually an adequate fixation. Other possibilities are the use of lag screws for oblique fractures of mandibular body, a hybrid technique with lag screw and miniplate ${ }^{8-9}, 2.4 \mathrm{~mm}$ reconstruction plate placed along the inferior border of the mandible or two in the mandibular tension and compression zone ${ }^{10}$.

Few studies have been published on the analysis of fixation techniques for mandibular body fractures ${ }^{5,7-8,10-11}$, and further research is needed relating to the biomechanical study of the different techniques for the internal fixation of mandibular body fractures. When evaluating the functional stability of the fixations by simulating the vectors and load intensity that they will be subjected to, the results may be associated with the clinical practice, which implicates the need for a model simulating the human mandible anatomy. For the present study, a polyurethane hemi-mandible replica, already reported in the literature, was employed as a substitute for the human mandible during the biomechanical tests ${ }^{12-13}$.

The literature offers no clear evidence that one rigid internal fixation technique for the treatment of simple (linear) fractures of the mandibular body is superior to another ${ }^{11}$. Therefore, the objective of this study was to evaluate the mechanical strength of plates and screws from the $2.0 \mathrm{~mm}$ system in two types of fixation techniques, using human hemi-mandible polyurethane resin replicas, subjected to mechanical linear load testing.

\section{Material and methods}

A rigid polyurethane hemi-mandible with teeth and standardized density of $200 \mathrm{~g} / \mathrm{L}$ was used for the tests, manufactured by Nacional ${ }^{\mathrm{TM}}$ (Franceschi \& Costa and Silva Ltda., Jaú, SP, Brazil). The samples were submitted to sectioning simulating mandibular body fracture (in the premolar and first molar regions), and fixed with plates and screws in accordance with their respective group by making a colorless chemically activated acrylic resin guide (Dental Vipi Ltda., Pirassununga, SP, Brazil) for standardizing the fixation

The samples were grouped as follows: Group 1: 5 polyurethane hemi-mandibles with rigid internal fixation system, using a Tóride ${ }^{\circledR} 2.0 \mathrm{~mm}$ system with 2 plates containing 4 titanium extension holes and screws linearly inserted with a $90^{\circ}$ angle to the hemi-mandible. The first plate was fixed to the tension zone using $2.0 \mathrm{~mm} \times 5 \mathrm{~mm}$ screws; the second was secured to the compression zone with $2.0 \mathrm{~mm} \times 11 \mathrm{~mm}$ screws (ure 1). Group 2: 5 polyurethane hemi-mandibles with an Erich arch-bar were secured to the tension zone, and one $2.00 \mathrm{~mm}$ system titanium plate with 4 fixed extension holes to the neutral zone with $2.0 \mathrm{~mm}$ x 5 $\mathrm{mm}$ screws, linearly arranged and inserted at $90^{\circ}$ angle o the hemi-mandible (Figure 2).
All samples were embedded in a block of pink bonding acrylic resin (Artigos Odontológicos Clássico Ltda., Campo

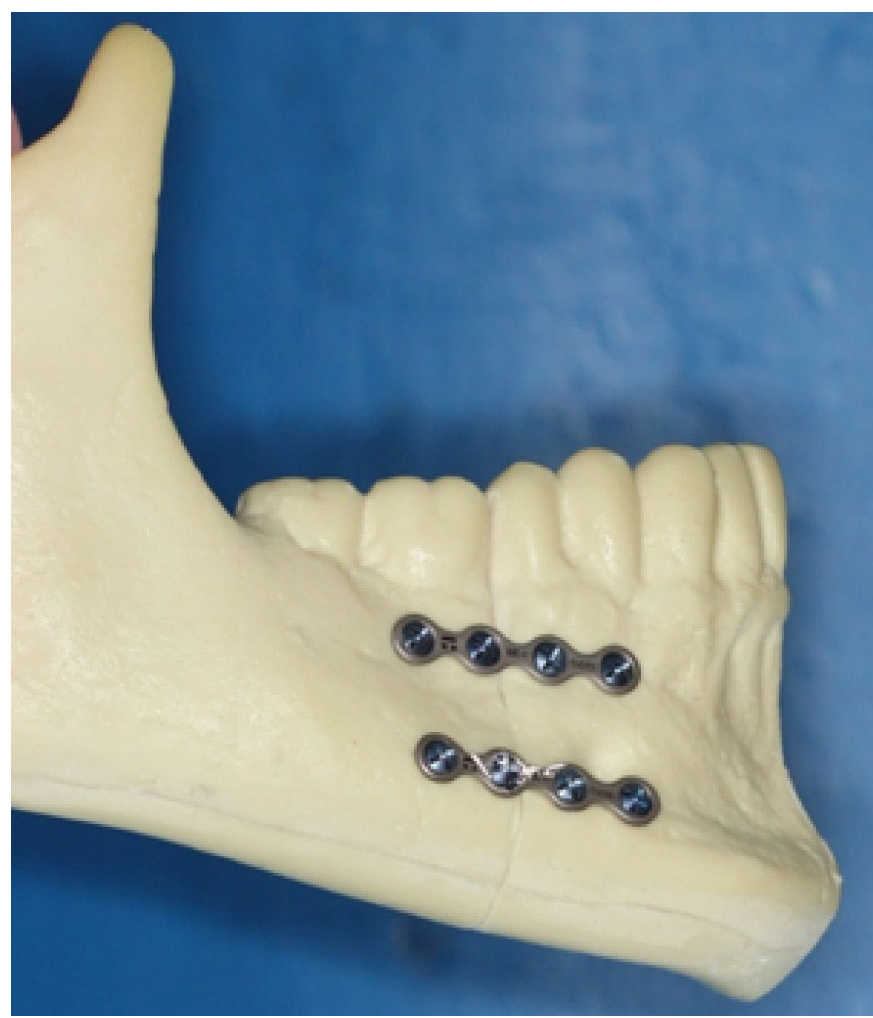

Fig. 1. Group 1: One $2.0 \mathrm{~mm}$ mini-plate in the compression zone and another one in the tension zone.

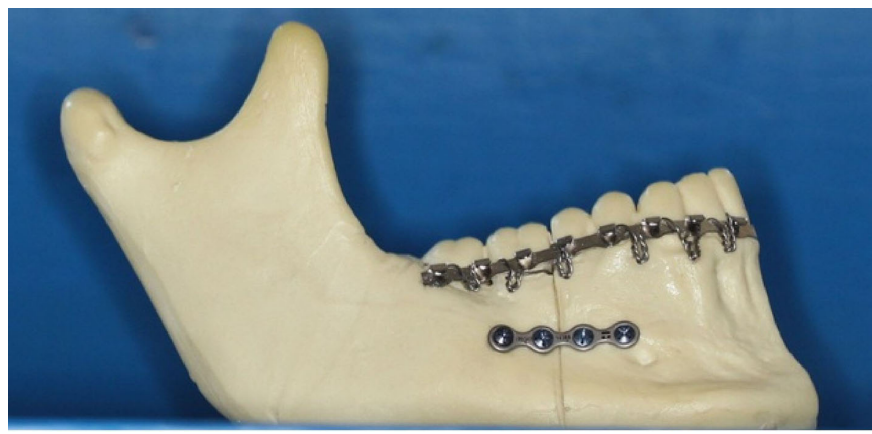

Fig. 2. Group 2: An Erich arch bar in the compression zone and one $2.0 \mathrm{~mm}$ miniplate in the neutral zone.

Limpo Paulista, SP, Brazil) to the full extent of the mandibular branch to allow its positioning and fixation to the holder during the test.

The load test was undertaken to evaluate the fastening systems resistance to the forces exerted on them. The load testing was performed in an Instron universal testing machine, (model 4411; Instron Corp., Norwood, MA, USA) at a crosshead speed of $1 \mathrm{~mm} / \mathrm{min}$ for applying progressive load (in $\mathrm{kgf}$ ) on the system. When the load resistance (peak and ultimate loads) was reached, the displacement $(\mathrm{mm})$ imposed by test was recorded in these two moments. The load was always applied on the distal segment at a fixed point, which received the device load, previously fabricated at the lingual canine region.

Data were analyzed statistically using the Student's ttest at 5\% significance level. 


\section{Results}

The peak load (kgf) and peak displacement ( $\mathrm{mm})$ means and standard deviations of the two test groups are presented in Tables 1 and 2.

The peak load values indicated significantly greater resistance for the fixation using two plates of $2.0 \mathrm{~mm}$ system compared with fixation with one plate of the $2.0 \mathrm{~mm}$ system and one Erich bar $(\mathrm{p}<0.05)$ (Figure 3$)$.

The peak displacement values indicated significantly greater displacement from the fixation using two plates of $2.0 \mathrm{~mm}$ system compared with the fixation with one plate of the $2.0 \mathrm{~mm}$ system and one Erich bar $(\mathrm{p}<0.05)$ (Figure 4).

\section{Discussion}

Isolated fractures of the mandibular body tend to displace the superior surface compressed towards the inferior surface

Table 1. Values of peak load and peak displacement in Group1

\begin{tabular}{lcc}
\hline Sample & Peak Load & Displacement Peak \\
1 & 28.47 & 9.48 \\
2 & 11.91 & 6.18 \\
3 & 16.07 & 10.27 \\
4 & 23.67 & 6.64 \\
5 & 19.17 & 9.54 \\
\hline
\end{tabular}

Table 2. Values of peak load and peak displacement in Group 2.

\begin{tabular}{lcc}
\hline Sample & Peak Load & Displacement Peak \\
1 & 26.38 & 9.01 \\
2 & 6.71 & 2.37 \\
3 & 11.34 & 3.07 \\
4 & 11.7 & 6.00 \\
5 & 9.101 & 2.89 \\
\hline
\end{tabular}

when subjected to masticatory forces. The superior surface is called tension zone (separation) while the lower edge is called compression zone. The fixation on the upper edge (dentate) is more effective in preventing the separation when the mandible is subjected to efforts ${ }^{7,14-15}$. Thus, when applying fixation materials to the mandible during fracture treatments, typically a plate is installed in the tension zone, where the bone surfaces are separated. This study is based on the principle that some kind of material is required in the tension zone, either an Erich bar or a fixation plate, during the force testing.

Various combinations of rigid internal fixation are available for mandibular body fractures: Two fixation plates are required, one in the tension zone with monocortical screws because of the presence of teeth, and one titanium plate in the compression zone with bicortical screws. Lag screws are reserved for oblique fractures and the maxillo-mandibular fixation for a more conservative approach. The rigid internal fixation technique can be performed with a $2.0 \mathrm{~mm}$ system plate, a combination of the $2.0 \mathrm{~mm}$ and the $2.4 \mathrm{~mm}$ systems, or a $2.4 \mathrm{~mm}$ system with an Erich $\operatorname{bar}^{6,8-10}$.

This way, evaluation of the different fixation methods is important to provide a direction for the stability and predictability of each option. This biomechanical study evaluated two forms of fixation for the surgical treatment of mandibular body fractures because there is no consensus on the routinely used methods ${ }^{11}$ and no studies were found comparing the combined use of the $2.0 \mathrm{~mm}$ mini-plate system in the neutral area and an Erich bar in the tension zone.

The biomechanical stability is an important factor in the choice of material to be used, although other factors influence the outcome of the treatment, since each technique presents clinical advantages and disadvantages that should be taken into consideration during the surgical planning. The use of two fixation plates increases the treatment cost due to the larger amount of material required, the risk of

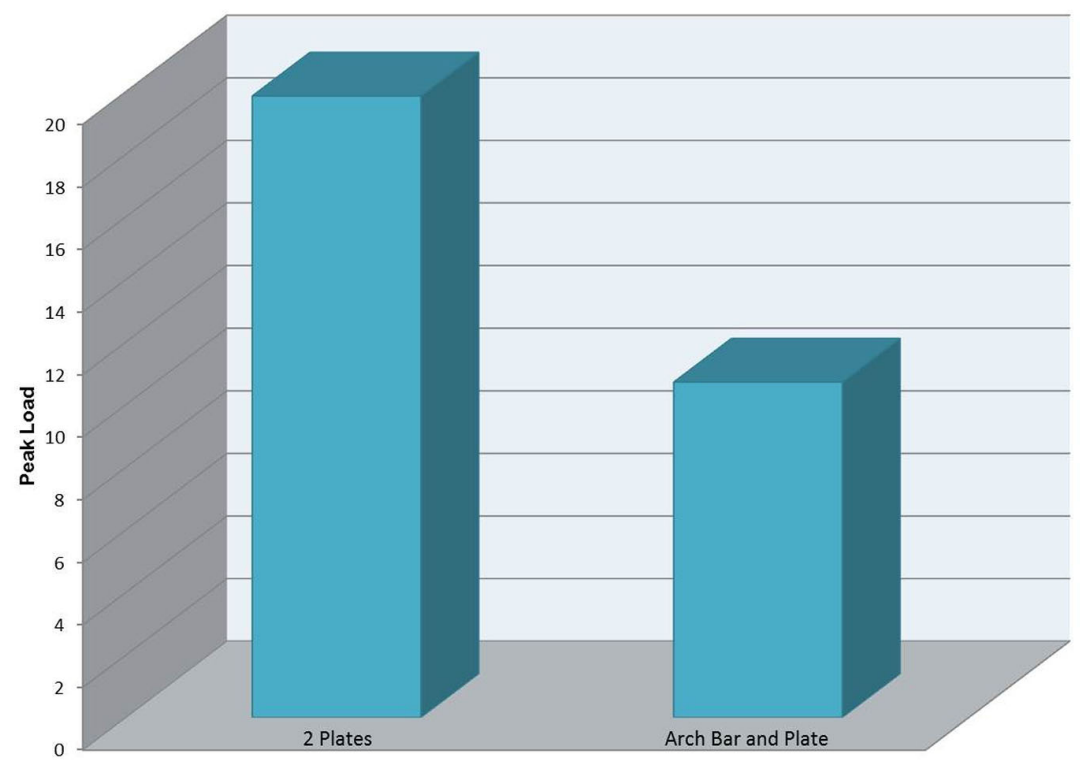

Fig. 3. Comparison os treatment depending on the peak load 


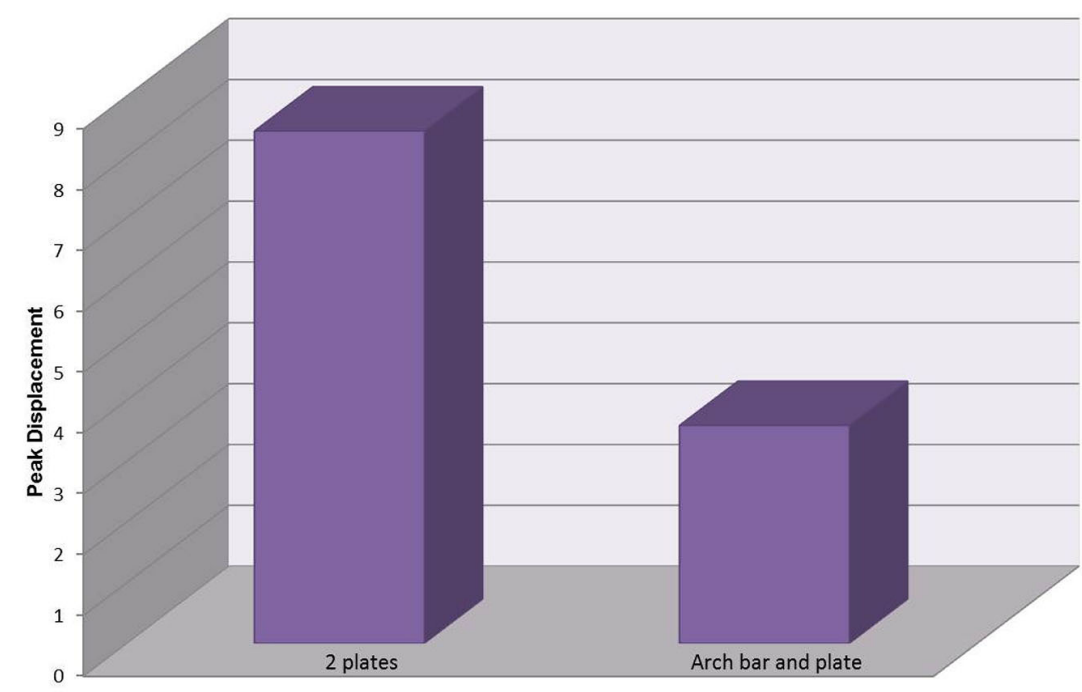

Fig. 4. Comparison of treatment depending on the peak displacement

iatrogenic injury to the tooth roots is increased when using the plate in the tension zone, and a greater chance of a wound dehiscence and exposure of the upper plate ${ }^{11}$. Despite its potential drawbacks, biomechanically, this technique had the best behavior in this study, requiring larger force for displacement and consequent failure.

The main advantage of using the Erich bar in combination with a fixation plate is associated with its low cost and versatility. Conversely, the patient must be dentated for the stabilization of the Erich bar (which can damage the periodontium due to the steel wires), and requires greater patient compliance during the postoperative period, especially in relation to hygiene and diet ${ }^{7}$.

It may be then concluded that the use of 2 plates in the $2.0 \mathrm{~mm}$ system is capable to withstand a greater load before failure. From a clinical perspective, it is known that both techniques can produce good results, but patients receiving the combination of Erich bar in the tension zone and a plate in the compression zone during treatment of a fractured mandible, should be more collaborative during the postoperative period, especially with respect to the prescribed diet in order to avoid failures in this system.

\section{Acknowledgments}

The authors would like to acknowledge Toride ${ }^{\circledR}$ (Tóride Indústria e Comércio Ltda. - Mogi Mirim, SP, Brasil) for their generous assistance in providing the fixation plates and screws for this study.

\section{References}

1. Martini MZ, Takahashi A, Oliveira Neto HG, Carvalho Júnior JP, Curcio $\mathrm{R}$, Shinohara EH. Epidemiology of Mandibular Fractures Treated in a Brazilian Level I Trauma Public Hospital in the City of São Paulo, Brazil. Braz Dent J. 2006; 17: 243-8.
2. Atilgan S, Erol B, Yaman F, Yilmaz N, Ucan MC. Mandibular fractures: a comparative analysis between young and adult patients in the southeast region of Turkey. J Appl Oral Sci. 2010; 18: 17-22.

3. Peterson JL, Ellis III E, Hupp JR, Tucker MR. Contemporary oral and maxillofacial surgery. 4th ed. Saint Louis: Mosby; 2002.

4. Fonseca RJ, Marciani RD, Turvey TA. Oral and maxillofacial surgery. 2nd ed. Saint Louis: Saunder Elsevier; 2009. v.2.

5. Sauerbier S, Schön R, Otten JE, Schmelzeisen R, Gutwald RJ. The development of plate osteosynthesis for the treatment of fractures of the mandibular body and a literature review. J Craniomaxillofac Surg. 2008; 36: 251-9.

6. Ellis III E. Treatment methods for fractures of the mandibular angle. Int J Oral Maxillofac Surg. 1999; 28: 243-52.

7. Miloro M, Ghali EG, Larsen EP, Waite DP. Peterson's principles of oral and maxillofacial surgery. Hamilton: BC Decker; 2004.

8. Ellis III E. Use of Lag Screws for Fractures of the Mandibular Body. J Oral Maxillofac Surg. 1996; 54: 1314-6.

9. Ramalho RA, Araújo FAC, Santos FSM, Caubi AF, Sobreira T. Management of the mandible fracture: miniplates and screws vs. lag screws - case report. Rev Cir Traumatol Buco-Maxilo-Facial. 2011; 11: 9-12.

10. Assael AL, Klotch WD, Manson NP, Prein J, Rahn AB, Schilli W. Manual of internal fixation in the cranio-facial skeleton. Berlin: Springer-Verlag; 1998.

11. Ellis III E. A study of 2 bone plating methods for fractures of the mandibular symphysis/body. J Oral Maxillofac Surg. 2011; 69: 1978-87.

12. Haug RH, Peterson GP, Goltz M. A biomechanical evaluation of mandibular condyle fracture plating techniques. J Oral Maxillofac Surg. 2002; 60: 73-80.

13. Ziccardi VB, Schneider RE, Kummer FJ, Wurzburg lag screw plate versus four hole miniplate for the treatment of condylar process fractures. J Oral Maxillofac Surg. 1997; 55: 602-7.

14. Ellis III E. Management of fractures through the angle of the mandible. Oral Maxillofacial Surg Clin N Am. 2009; 21: 163-74.

15. Kimsal J, Baack B, Candelaria L, Khraishi T, Lovald S. Biomechanical analysis of mandibular angle fractures. J Oral Maxillofac Surg. 2011; 69: 3010-4. 